\title{
openheart Comparative analysis and meta-analysis of major clinical trials with oral factor $X a$ inhibitors versus warfarin in atrial fibrillation
}

\author{
José Pedro L Nunes, Rui Paulo Rodrigues, Francisco Rocha Gonçalves
}

To cite: Nunes JPL, Rodrigues RP, Gonçalves FR. Comparative analysis and meta-analysis of major clinical trials with oral factor Xa inhibitors versus warfarin in atrial fibrillation. Open Heart 2014;1:e000080. doi:10.1136/openhrt-2014000080

Received 21 February 2014 Revised 5 June 2014 Accepted 15 July 2014
Department of Medicine, Faculdade de Medicina da Universidade do Porto, Porto, Portugal

Correspondence to Dr José Pedro L Nunes; jplnunes@med.up.pt

\section{ABSTRACT}

Objectives: A comparative analysis of three major clinical trials with factor $X a$ inhibitor oral anticoagulant (XOAC) drugs versus warfarin in atrial fibrillationRocket-AF (rivaroxaban), Aristotle (apixaban) and Engage AF Timi 48 (edoxaban; two different doses and sets of data)-was carried out.

Methods: Data were extracted from the original reports (study level) and a meta-analysis was carried out.

Results: When compared with warfarin, XOAC therapy was associated with a decrease in haemorrhagic stroke, with a similar pattern for all regimens and meta-analysis showing a risk ratio of $0.488(95 \% \mathrm{Cl}$ 0.396 to 0.601 ). Regarding total mortality, a favourable pattern was seen for all four regimens and metaanalysis showed a risk ratio of $0.892(95 \% \mathrm{Cl} 0.840$ to 0.947). Major bleeding and gastrointestinal bleeding provided two examples regarding which heterogeneity would seem to exist, when XOAC drugs are compared with warfarin. In what concerns the incidence of myocardial infarction, the primary end point (stroke plus systemic embolism) and ischaemic stroke, the situation is less clear. These results are inconsistent with a putative 'group effect' for all the seven parameters under study, and for some of them it would probably be best to look at each of the individual trial data rather than at the meta-analysis data (which seem to lack a clear biological meaning).

Conclusions: Apixaban, rivaroxaban and edoxaban have shown interesting effects, when compared with warfarin in clinical trials, in patients with atrial fibrillation, particularly with regard to haemorrhagic stroke and to the mortality rate. No other consistent conclusions concerning a putative 'group effect' can be reached at the present stage. Concerns regarding adherence to therapy, possible drug interactions, cost and current absence of antidotes may be taken into consideration when choosing an anticoagulant drug.

\section{INTRODUCTION}

Atrial fibrillation (AF) is a condition associated with important complications, including stroke. ${ }^{1}$ Anticoagulation with warfarin

\section{KEY MESSAGES}

What is already known about this subject?

- Clinical trials using three different drugs with factor Xa inhibitor activity have been published in atrial fibrillation, in each case compared with warfarin. Some previous meta-analyses, unlike the present one, have included data obtained with a drug with a different mechanism of action.

What does this study add?

- A "class effect" may exist for these drugs in what concerns total mortality and haemorrhagic stroke (both decreased, when compared to warfarin therapy), but not for other outcomes, such as major bleeding and gastrointestinal bleeding. The characteristics of trial design may have played a role in the heterogeneity seen with some outcomes.

How might this impact on clinical practice?

- Clinicians may obtain a clear view on what can be expected when using any of the three drugs under analysis, in patients with atrial fibrillation, when compared to warfarin, and what can be expected from each individual drug and regimen, information to be added to other aspects when considering anticoagulation in this setting.

leads to a decreased incidence of thromboembolic events in patients with $\mathrm{AF}^{2}{ }^{3}$ Warfarin therapy in AF is associated with significant side effects, namely haemorrhagic phenomena. Warfarin use implies INR (international normalised ratio) monitoring, since genetic aspects ${ }^{4}$ and interactions with food and other drugs are not uncommon. These aspects have resulted in an interest in developing new therapeutic approaches.

New anticoagulant drugs have been presented, with mechanisms of action different from warfarin: dabigatran, ${ }^{5}$ a thrombin inhibitor, and apixaban, ${ }^{6}$ rivaroxaban ${ }^{7}$ and 
Table 1 General overview of the three trials with factor Xa inhibitors versus warfarin

\begin{tabular}{|c|c|c|c|}
\hline & Aristotle apixaban & Rocket-AF rivaroxaban & Engage AF edoxaban \\
\hline $\begin{array}{l}\text { Total number of } \\
\text { patients }\end{array}$ & 18201 & 14264 & 21105 \\
\hline Primary end point & Stroke or systemic embolism & $\begin{array}{l}\text { Stroke or systemic } \\
\text { embolism }\end{array}$ & Stroke or systemic embolism \\
\hline $\begin{array}{l}\text { Drug dose (factor } \\
\text { Xa inhibitor) }\end{array}$ & $\begin{array}{l}5 \mathrm{mg} \text { twice daily; } 2.5 \mathrm{mg} \text { with two } \\
\text { or more of: age } \geq 80 \text { years, body } \\
\text { weight } \leq 60 \mathrm{~kg} \text {, serum creatinine } \\
\geq 1.5 \mathrm{mg} / \mathrm{dL}\end{array}$ & $\begin{array}{l}20 \mathrm{mg} \text { daily; } 15 \mathrm{mg} \text { daily in } \\
\text { patients with creatinine } \\
\text { clearance } 30-49 \mathrm{~mL} / \mathrm{min}\end{array}$ & $\begin{array}{l}\text { Either } 60 \text { or } 30 \mathrm{mg} \text {; half dose if: } \\
\text { creatinine clearance of } 30-50 \mathrm{~mL} / \mathrm{min} \text {, } \\
\text { body weight } \leq 60 \mathrm{~kg} \text {, concomitant use } \\
\text { of } P \text {-glycoprotein inhibitors }\end{array}$ \\
\hline Pretrial risk & $\begin{array}{l}\text { CHADS2 score of } 1 \text { or higher } \\
\text { (mean of } 2.1 \text { ) }\end{array}$ & $\begin{array}{l}\text { CHADS2 score of } 2 \text { or } \\
\text { higher (mean of } 3.5 \text { ) }\end{array}$ & $\begin{array}{l}\text { CHADS2 score of } 2 \text { or higher (mean of } \\
2.8 \text { ) }\end{array}$ \\
\hline $\begin{array}{l}\text { Median age } \\
\text { (years) }\end{array}$ & 70 & 73 & 72 \\
\hline $\begin{array}{l}\text { INR in therapeutic } \\
\text { range (warfarin } \\
\text { group) }\end{array}$ & Median of $66 \%$ & Median of $58 \%$ & Median of $68.4 \%$ \\
\hline Arrhythmia & Atrial fibrillation or flutter & $\begin{array}{l}\text { Non-valvular atrial } \\
\text { fibrillation }\end{array}$ & Atrial fibrillation \\
\hline Median follow-up & 1.8 years & 707 days & 2.8 years \\
\hline Aspirin use (\%) & $30.5-31.3$ & $36.3-36.7$ & $28.7-29.7$ \\
\hline
\end{tabular}

edoxaban, ${ }^{8}$ as factor $\mathrm{Xa}$ inhibitor oral anticoagulant (XOAC) drugs. In what concerns factor Xa inhibitors, the three aforementioned drugs have shown interesting effects in patients with AF, in large clinical trials carried out with warfarin as the comparator drug. ${ }^{6-8}$

The purpose of the present report was to compare the major results obtained with each of the three XOAC drugs, not only by analysing the clinical trial data, but also by carrying out a meta-analysis, aiming at the possible identification of patterns common to the different XOAC therapies. Since edoxaban was used in two different dosages in the Engage-AF Timi 48 trial, four different sets of data are in fact available. Data obtained with dabigatran were not used, since the drug has a different mechanism of action, and the inclusion of dabigatran data would lack biological meaning.

\section{METHODS}

Data were independently retrieved by two authors from the original reports: Aristotle, ${ }^{6}$ Rocket- $\mathrm{AF}^{7}$ and Engage
AF Timi $48^{8}$ (data retrieved at study level). 'Intention to treat' data were used whenever available. Meta-analysis was carried out by using the Comprehensive Meta-analysis Software, V.2.0 (Biostat, New Jersey, USA). Random-effects analyses were carried out, given the considerable heterogeneity of the data. ${ }^{9}$

For the purpose of the meta-analysis, the data from the two edoxaban arms in the Engage AF trial ${ }^{8}$ were taken together, since one single warfarin control group existed. Risk ratios and $95 \%$ CIs are presented.

The parameters chosen for analysis and also for the meta-analysis were the primary end point (stroke plus systemic embolism for the three studies), total mortality, myocardial infarction, ischaemic stroke, haemorrhagic stroke, major bleeding and gastrointestinal bleeding.

\section{RESULTS}

A general overview of the three trials is presented in table 1, including data on the number of patients, primary end point chosen, drug dosage, CHADS2 score

Table 2 Major results of the three trials with factor Xa inhibitors versus warfarin (data are $n / N$ )

\begin{tabular}{|c|c|c|c|c|c|c|c|}
\hline & \multicolumn{2}{|l|}{ Aristotle } & \multicolumn{2}{|l|}{ Rocket-AF } & \multicolumn{3}{|l|}{ Engage AF } \\
\hline & Apixaban & Warfarin & Rivaroxaban & Warfarin & $\begin{array}{l}\text { Edoxaban } \\
60 \mathrm{mg}\end{array}$ & $\begin{array}{l}\text { Edoxaban } \\
30 \mathrm{mg}\end{array}$ & Warfarin \\
\hline Primary end point & $212 / 9120^{*}$ & $265 / 9081$ & $269 / 7081$ & $306 / 7090$ & $296 / 7035$ & $383 / 7034$ & $337 / 7036$ \\
\hline Mortality & $603 / 9120^{*}$ & $669 / 9081$ & $208 / 7061$ & $250 / 7082$ & $773 / 7035$ & $737 / 7034^{\star}$ & $839 / 7036$ \\
\hline Ischaemic stroke & $149 / 9120$ & $155 / 9081$ & $149 / 7061$ & $161 / 7082$ & $236 / 7035$ & $333 / 7034^{\star}$ & $235 / 7036$ \\
\hline Haemorrhagic stroke & $40 / 9120^{\star}$ & $78 / 9081$ & $29 / 7061^{*}$ & $50 / 7082$ & $49 / 7035^{\star}$ & $30 / 7034^{*}$ & $90 / 7036$ \\
\hline Myocardial infarction & $90 / 9120$ & $102 / 9081$ & $101 / 7061$ & $126 / 7082$ & $133 / 7035$ & $169 / 7034$ & $141 / 7036$ \\
\hline Major bleeding & $327 / 9088^{*}$ & $462 / 9052$ & $395 / 7111$ & $386 / 7125$ & $418 / 7012^{*}$ & $254 / 7002^{*}$ & $524 / 7012$ \\
\hline Gastrointestinal bleeeding & $105 / 9088$ & $119 / 9052$ & $224 / 7111^{*}$ & $154 / 7125$ & $232 / 7012^{*}$ & $129 / 7002^{*}$ & $190 / 7012$ \\
\hline
\end{tabular}


Figure 1 Meta-analysis of three clinical trials with factor $\mathrm{Xa}$ inhibitors versus warfarin. Data on total mortality. Heterogeneity: $\mathrm{l}^{2}=0.000 ; p=0.747$ (XOAC, factor Xa inhibitor oral anticoagulant).

Figure 2 Meta-analysis of three clinical trials with factor $\mathrm{Xa}$ inhibitors versus warfarin. Data on the primary end point (stroke plus systemic embolism).

Heterogeneity: $I^{2}=57.866$; $\mathrm{p}=0.093$ (XOAC, factor $\mathrm{Xa}$ inhibitor oral anticoagulant).

Figure 3 Meta-analysis of three clinical trials with factor $\mathrm{Xa}$ inhibitors versus warfarin. Data on myocardial infarction.

Heterogeneity: $I^{2}=39.108$;

$\mathrm{p}=0.194$ (XOAC, factor $\mathrm{Xa}$

inhibitor oral anticoagulant).

Figure 4 Meta-analysis of three clinical trials with factor $\mathrm{Xa}$ inhibitors versus warfarin. Data on ischaemic stroke. Heterogeneity: $\mathrm{l}^{2}=61.462 ; p=0.075$ (XOAC, factor $X a$ inhibitor oral anticoagulant).

Figure 5 Meta-analysis of three clinical trials with factor $\mathrm{Xa}$ inhibitors versus warfarin. Data on haemorrhagic stroke. Heterogeneity: $l^{2}=0.000 ; p=0.577$ (XOAC, factor Xa inhibitor oral anticoagulant).

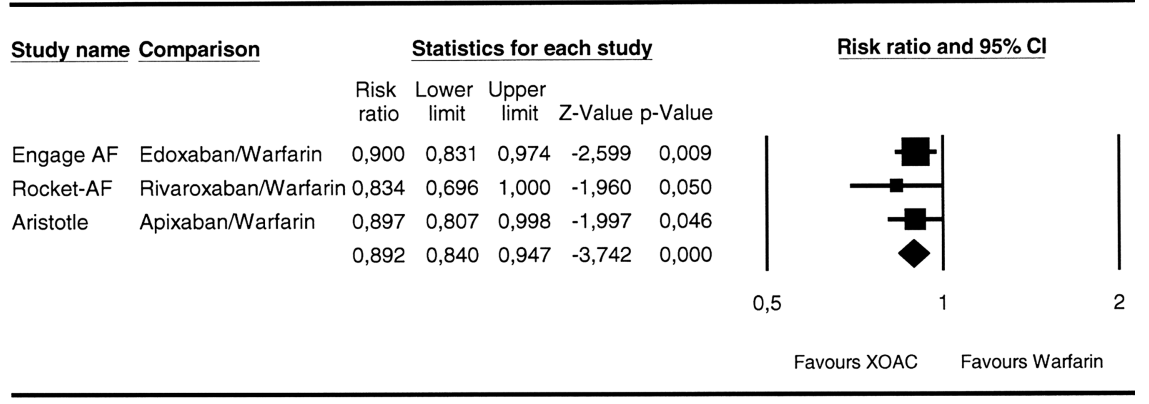

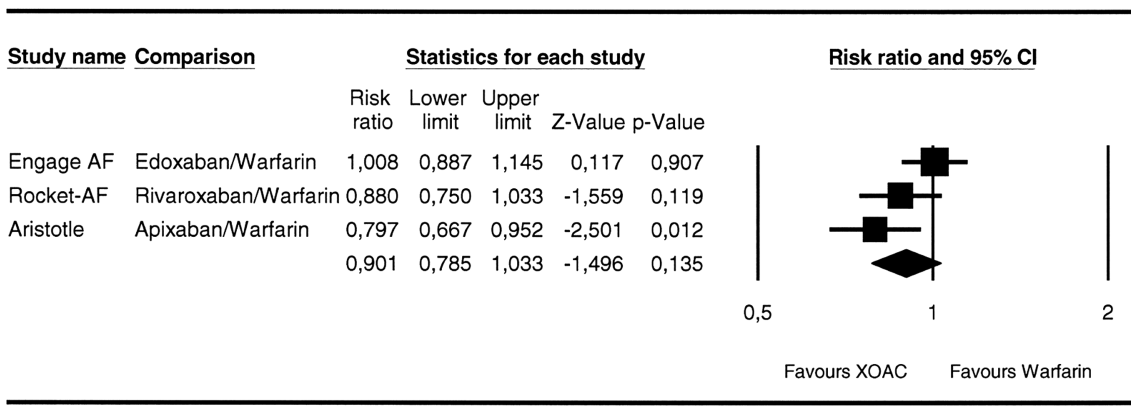

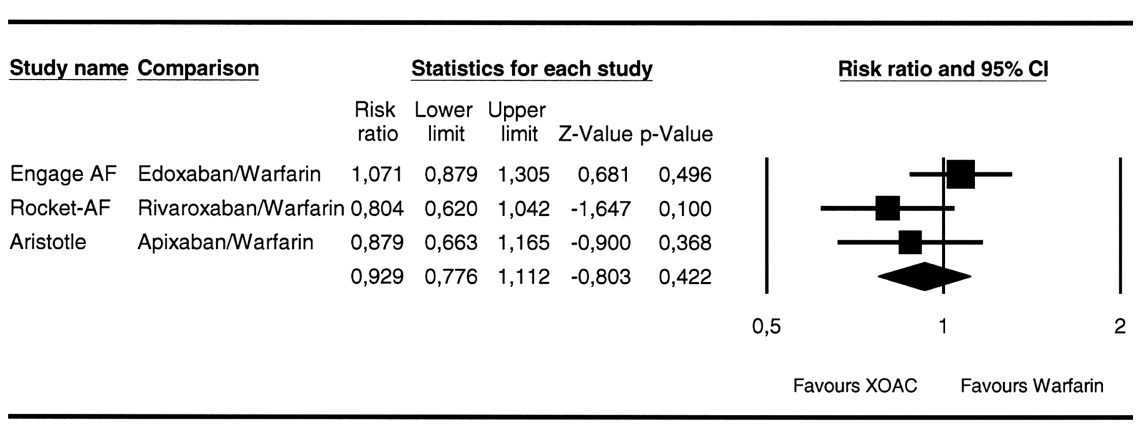

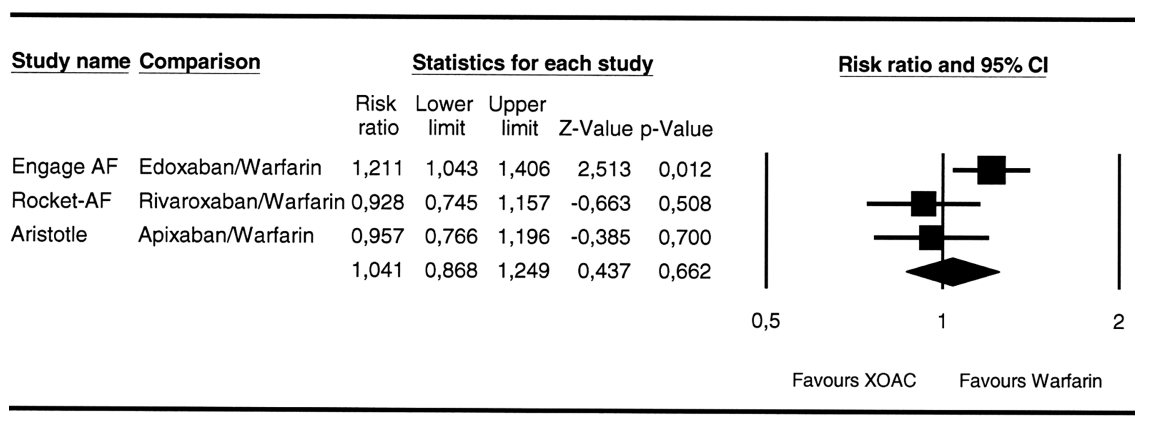

\begin{tabular}{|c|c|c|c|c|c|c|c|c|c|c|c|c|}
\hline \multirow[t]{2}{*}{ Study name } & \multirow[t]{2}{*}{ Comparison } & \multicolumn{5}{|c|}{ Statistics for each study } & \multicolumn{6}{|c|}{ Risk ratio and $95 \% \mathrm{CI}$} \\
\hline & & $\begin{array}{l}\text { Risk } \\
\text { ratio }\end{array}$ & $\begin{array}{c}\text { Lower } \\
\text { limit }\end{array}$ & $\begin{array}{l}\text { Upper } \\
\text { limit }\end{array}$ & Z-Value & -Value & & & & & & \\
\hline Engage AF & Edoxaban/Warfarin & 0,439 & 0,325 & 0,593 & $-5,364$ & 0,000 & & & & & & \\
\hline Rocket-AF & Rivaroxaban/Warfarin & 0,582 & 0,369 & 0,918 & $-2,327$ & 0,020 & & & & & & \\
\hline \multirow[t]{4}{*}{ Aristotle } & Apixaban/Warfarin & 0,511 & 0,349 & 0,747 & $-3,466$ & 0,001 & & & & & & \\
\hline & & 0,488 & 0,396 & 0,601 & $-6,716$ & 0,000 & & & & & & \\
\hline & & & & & & & 0,1 & 0,2 & 0,5 & 2 & 5 & 10 \\
\hline & & & & & & & & Favou & $S$ XOAC & Eavou & Varfar & \\
\hline
\end{tabular}


Figure 6 Meta-analysis of three clinical trials with factor $\mathrm{Xa}$ inhibitors versus warfarin. Data on major bleeding. Heterogeneity: $\mathrm{l}^{2}=93.005 ; \mathrm{p}=0.000$ (XOAC, factor Xa inhibitor oral anticoagulant).

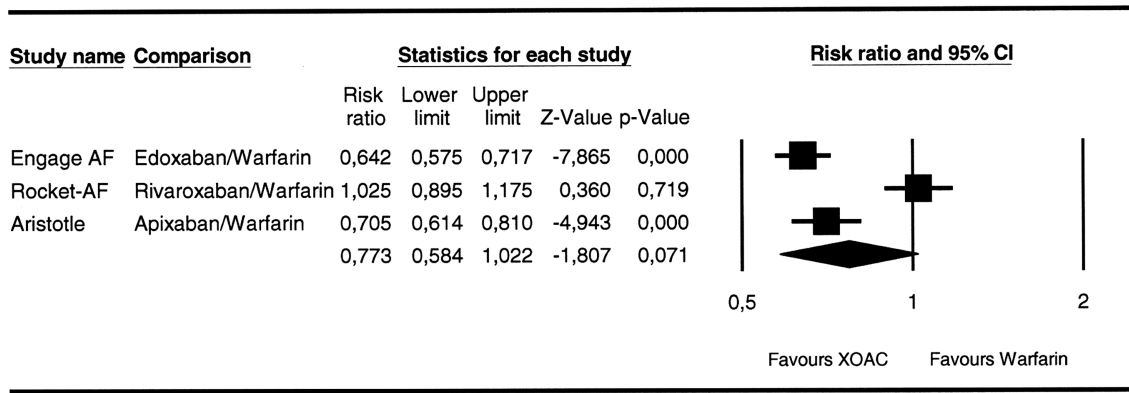

of the patients, median age, type of arrhythmia, percentage of INR in therapeutic range for the warfarin group and duration of median follow-up. A significant degree of heterogeneity was seen: different drugs were used in the three trials, with different criteria for patient selection, different times of follow-up, once daily administration for rivaroxaban and edoxaban, versus twice daily for apixaban, two different dosages for edoxaban. The patients under study in the three trials did not have the same degree of risk of thromboembolic events, with different mean values for the CHADS2 score (table 1).

The major results from the three reports are presented in table 2 and in figures 1-7.

The largest reduction associated with XOAC therapy was seen with haemorrhagic stroke, with a similar pattern for all regimens and meta-analysis showing a risk ratio of 0.488 (95\% CI 0.396 to 0.601$)$.

Regarding total mortality, XOAC therapy also showed a favourable pattern for all four regimens, and meta-analysis showed a risk ratio of $0.892(95 \%$ CI 0.840 to 0.947$)$. Apixaban therapy was associated with decreased mortality when compared with warfarin. Interestingly, low-dose edoxaban therapy was also associated with significantly lower values for haemorrhagic stroke and total mortality.

In what concerns the primary end point, stroke plus systemic embolism, apixaban showed a significantly favourable effect, when compared with warfarin, the opposite being observed with a low dose of edoxaban.

With respect to myocardial infarction, a similar pattern was observed, with low-dose edoxaban associated with results in the opposite direction than the other three alternatives, when compared with warfarin; however, none of the values observed reached significance level.

Regarding ischaemic stroke, low-dose edoxaban therapy was associated with a significantly higher number of episodes, when compared with warfarin, unlike the other three regimens.

Major bleeding was lower with apixaban and with both doses of edoxaban, when compared with warfarin, but not with rivaroxaban.

Regarding gastrointestinal bleeding, high-dose edoxaban and rivaroxaban therapies were associated with worse results than warfarin, while low-dose edoxaban had better results.

\section{DISCUSSION}

Controlled clinical trials are a major method to establish the effects of drugs in humans since, unlike epidemiological studies, clinical trials may have strong internal validity and may establish a nexus of causality. ${ }^{10}$ However, a better understanding of the effects of drugs frequently occurs only after a given drug is in general use for some years, namely in what concerns the discovery of rare side effects.

The results reported in the three clinical trials with factor Xa inhibitors apixaban, rivaroxaban and edoxaban, compared in each case to warfarin, yielded a relatively clear image on the therapeutic interest of these three drugs in AF. The present comparative analysis of XOAC drugs has shown a significant degree of heterogeneity of effects. Pharmacological differences between
Figure 7 Meta-analysis of three clinical trials with factor $\mathrm{Xa}$ inhibitors versus warfarin. Data on gastrointestinal bleeding. Heterogeneity: $I^{2}=84.486$; $\mathrm{p}=0.002$ (XOAC, factor $\mathrm{Xa}$ inhibitor oral anticoagulant).

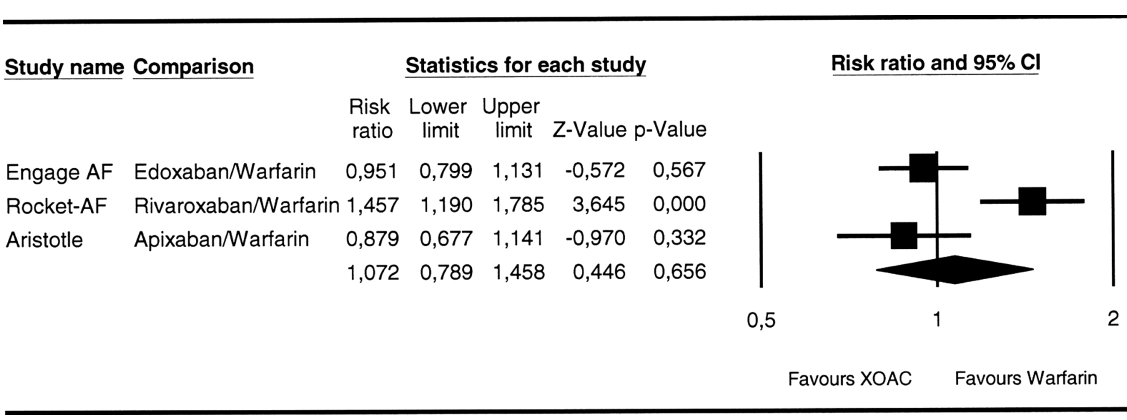


drugs could be at play. These drugs, having a narrow therapeutic range, could depend critically on the design of the clinical trials, in what respects the observed effects. Dramatic differences in the effects of edoxaban according to the dose used, ${ }^{8}$ similar to what had been observed with dabigatran, ${ }^{5}$ strongly point in the latter direction. In the case of edoxaban in the Engage AF trial, two different dosages of the drug were under study, ${ }^{8}$ but the low dose of edoxaban was associated with the lowest mortality, possibly in association with the also lowest number of major bleeding events. ${ }^{8}$

Four different therapeutic regimens have been studied with XOAC drugs, to be added to further two with dabigatran. Each regimen yielded its own set of effects, and the different sets of effects were in fact quite different. What, if any, are the common characteristics of the effects of XOAC drugs under the regimens studied in patients with AF? The present report attempts to provide an answer to this question.

Seven types of outcomes are under analysis in this report. For some of them, a similar pattern seems to exist for the different XOAC drugs, whereas the same does not seem to happen regarding other outcomes.

The mortality rate was decreased in association with the three XOAC drugs, when compared with warfarin therapy, by about one-tenth. Haemorrhagic stroke also seems to be clearly decreased under these three XOAC drugs, when compared with warfarin. In fact, the incidence of haemorrhagic stroke under the three XOAC drugs was about half the incidence seen under warfarin therapy. These two effects would seem to be associated with factor Xa inhibition therapy.

On the other hand, major bleeding and gastrointestinal bleeding provided two examples regarding which heterogeneity would seem to exist when XOAC drugs are compared with warfarin.

In what concerns the incidence of myocardial infarction, the primary end point (stroke plus systemic embolism) and ischaemic stroke, the situation is less clear. These results are inconsistent with a putative 'group effect' for all the seven parameters under study. The interest of the meta-analysis data would seem to be confined to the end points regarding sets of data consistent with a 'group effect' (the group consisting of apixaban, rivaroxaban and edoxaban). In what concerns end points with data on both sides of the unity line and with at least one significant value, the meta-analytical numerical conclusion would seem to be devoid of any clear biological meaning, given the heterogeneity in the trial conditions, and it would probably be best to evaluate the data from each clinical trial separately.

Ruff $e t a l^{11}$ published a meta-analysis including the three trials with factor Xa inhibitor drugs and also the thrombin inhibitor, dabigatran, and removing the data obtained with the low drug doses from the main study. The conclusions regarding haemorrhagic stroke and total mortality are similar to the conclusions on these end points now reported; however, different conclusions were reached in other end points, namely gastrointestinal bleeding.

Gastrointestinal bleeding associated with XOAC drugs, in fact, surpassed the figures for warfarin in the case of rivaroxaban and of high-dose edoxaban, drugs used once daily, but not in the trial with twice daily drug use (apixaban) or with low-dose edoxaban. One can speculate that pharmacokinetic aspects/peak intensity of factor Xa inhibition/choice of drug doses/once versus twice daily use may stand behind some of the findings on this topic. In any event, it would certainly not appear that increased gastrointestinal bleeding is a necessary consequence of XOAC drug therapy, when compared with warfarin.

It is yet to be fully understood how these drugs compare with warfarin in 'real-world' situations. Concerns regarding adherence to therapy, possible drug interactions, cost and current absence of antidotes may be taken into consideration when choosing an anticoagulant drug. ${ }^{12}$

Study limitations: Data were obtained at study level (from the original publications) meta-analysis of data from the Engage AF trial used aggregate data from patients under the two edoxaban dosages, thus limiting the heterogeneity evaluation presented in the legend of the figures.

In conclusion, apixaban, rivaroxaban and edoxaban have shown interesting effects, when compared with warfarin, in patients with AF. The incidence of haemorrhagic stroke under the three XOAC drugs is about half the incidence seen under warfarin therapy, whereas the mortality rate is also decreased by about one-tenth. No other clear and consistent conclusions concerning a putative 'group effect' can be reached at the present stage.

Contributors All authors contributed to the manuscript. JPLN was involved in data extraction, writing of the manuscript, meta-analysis and critical evaluation of content. RPR was involved in data extraction and a critical evaluation of content. FRG was involved in critical evaluation of content.

\section{Competing interests None.}

Provenance and peer review Not commissioned; externally peer reviewed.

Open Access This is an Open Access article distributed in accordance with the Creative Commons Attribution Non Commercial (CC BY-NC 3.0) license, which permits others to distribute, remix, adapt, build upon this work noncommercially, and license their derivative works on different terms, provided the original work is properly cited and the use is non-commercial. See: http:// creativecommons.org/licenses/by-nc/3.0/

\section{REFERENCES}

1. Wolf PA, Abbott RD, Kannel WB. Atrial fibrillation: a major contributor to stroke in the elderly. The Framingham Study. Arch Intern Med 1987;147:1561-4.

2. Petersen P, Boysen G, Godtfredsen J, et al. Placebo-controlled, randomised trial of warfarin and aspirin for prevention of thromboembolic complications in chronic atrial fibrillation. The Copenhagen AFASAK study. Lancet 1989;333:175-9.

3. Hart RG, Pearce LA, Aguilar MI. Meta-analysis: antithrombotic therapy to prevent stroke in patients who have nonvalvular atrial fibrillation. Ann Intern Med 2007;146:857-67. 
4. Rieder MJ, Reiner AP, Gage BF, et al. Effect of VKORC1 haplotypes on transcriptional regulation and warfarin dose. $N$ Engl J Med 2005;352:2285-93.

5. Connolly SJ, Ezekowitz MD, Yusuf S, et al. Dabigatran versus warfarin in patients with atrial fibrillation. N Engl J Med 2009;361:1139-51.

6. Granger CB, Alexander JH, McMurray JJV, et al. Apixaban versus warfarin in patients with atrial fibrillation. N Engl J Med 2011;365:981-92.

7. Patel MR, Mahaffey KW, Garg J, et al. Rivaroxaban versus warfarin in nonvalvular atrial fibrillation. N Engl J Med 2011;365:883-91.

8. Giugliano RP, Ruff CT, Braunwald E, et al. Edoxaban versus warfarin in patients with atrial fibrillation. $N$ Engl J Med 2013;369:2093-104.
9. Higgins JPT, Green S. Cochrane handbook for systematic reviews of interventions. Chichester: Wiley-Blackwell, 2008.

10. Nunes JPL. Medical therapeutics: from induction to scientific evolution. Perspect Biol Med 2013;56:568-83.

11. Ruff CT, Giugliano RP, Braunwald E, et al. Comparison of the efficacy and safety of new oral anticoagulants with warfarin in patients with atrial fibrillation: a meta-analysis of randomised trials. Lancet 2014;383:955-62.

12. Heidbuchel $\mathrm{H}$, Verhamme $\mathrm{P}$, Alings $\mathrm{M}$, et al. European Heart Rhythm Association Practical Guide on the use of new oral anticoagulants in patients with non-valvular atrial fibrillation. Europace 2013;15:625-51. 